Article

\title{
PRGF-Modified Collagen Membranes for Guided Bone Regeneration: Spectroscopic, Microscopic and Nano-Mechanical Investigations
}

\author{
Cristian Ratiu ${ }^{1, \dagger}$, Marcel Brocks ${ }^{1,+}$, Traian Costea ${ }^{2}$, Liviu Moldovan ${ }^{3}$ and Simona Cavalu $1, *$ (i) \\ 1 Faculty of Medicine and Pharmacy, University of Oradea, P-ta 1 Decembrie 10, 410081 Oradea, Romania; \\ cristianadrianratiu@gmail.com (C.R.); physioempathie@gmail.com (M.B.) \\ 2 Advanced Materials Research Laboratory, University of Oradea, 1 Universității Street, 410087 Oradea, \\ Romania; costea.traian.octavian@gmail.com \\ 3 Faculty of Electrical Engineering and Information Technology, University of Oradea, 1 University St., \\ 410087 Oradea, Romania; liviu@uoradea.ro \\ * Correspondence: simona.cavalu@gmail.com; Tel.: +40-722352756 \\ + Authors with equal contribution.
}

Received: 6 February 2019; Accepted: 8 March 2019; Published: 12 March 2019

\begin{abstract}
The aim of our study was to evaluate the properties of different commercially available resorbable collagen membranes for guided bone regeneration, upon addition of plasma rich in growth factors (PRGF). The structural and morphological details, mechanical properties, and enzymatic degradation were investigated in a new approach, providing clinicians with new data in order to help them in a successful comparison and better selection of membranes with respect to their placement and working condition. Particular characteristics such as porosity, fiber density, and surface topography may influence the mechanical behavior and performances of the membranes, as revealed by SEM/AFM and nanoindentation measurements. The mechanical properties and enzymatic degradation of the membranes were analyzed in a comparative manner, before and after PRGF-modification. The changes in Young modulus values are correlated with the ultrastructural properties of each membrane type. The enzymatic (trypsin) degradation test also emphasized that PRGF-modified membranes exhibit a slower degradation compared to the native ones.
\end{abstract}

Keywords: collagen; guided bone regeneration; membrane; nanoindentation

\section{Introduction}

The concepts of guided tissue regeneration and guided bone regeneration (GTR, GBR) were established more than 50 years ago, involving the placement of mechanical barriers between the soft tissue and residual bone. In this manner, the fast proliferation of epithelial cells into the bony defect is prevented. Additionally, the barriers protect and isolate the bone defect from the surrounding connective tissue, allowing a direct access for osteoblast progenitors to the desired site [1-3]. According to literature, barrier membranes designed for medical (dental) applications should meet the following criteria: biocompatibility, integration by the host tissues, exhibition of space-making and cell occlusion properties, permeability for nutrients, and clinical manageability $[4,5]$.

In order to achieve the specific geometry required for functional reconstruction, the material should also be appropriately malleable and the stiffness should sustain the pressure and mastication forces. On the other hand, an ideal barrier membrane should keep these properties for an extended period and, after the complete bone regeneration, should be integrated with the surrounding tissue.

Numerous barrier membranes have been developed in the last decades, which can be classified as resorbable or non-resorbable membranes. Non-resorbable membranes are primarily made of 
titanium and polytetrafluoroethylene, with good biocompatibility [6-8], aiming to maintain their structural integrity and the space beneath the membrane for a sufficient period. The main advantage is considered to be their predictability in terms of performance, and, hence, a reduced risk of long-term complications [9]. The main drawback in using this type of membrane is the necessity for its removal with a second-stage surgery. On the other hand, the advantage of bioabsorbable membranes, either synthetic (aliphatic polyesters) or natural (collagen), is their biochemical pathway resorption over time [1]. However, their main disadvantage is their unpredictability in terms of degree of resorption, with possible consequences regarding lack of rigidity [10-13].

Being the main component of periodontal and connective tissues, collagen-based degradable membranes are extensively used for GTR or GBR procedures. Collagen can be extracted industrially from bovine and porcine dermis and tendons, but during the manufacturing processes, significant structural changes may occur [14,15]. However, extracted collagen can be modified according to the medical purpose, resulting different forms adapted to medical applications such as GBR and GTR $[14,16]$.

Different types of collagen membranes, with different degrees of biodegradability, have been developed in the last decade, in order to optimize treatment strategies $[1,2,10,17]$.

The ongoing research in this field aims to develop an ideal membrane for GBR and GTR; every membrane type offers both advantages and disadvantages, but none exactly match the need of the final user-the clinician or the dentist. Continuous research is dedicated to this topic, based on the understanding of the benefits and limitations.

On the other hand, plasma rich in growth factors (PRGF) of autologous origin have previously been demonstrated to introduce several advantages, including the enhancement and acceleration of bone regeneration and, additionally, fast and predictable soft tissue healing [18-21]. Once the platelets become activated, the growth factors and cytokines within the alpha and dense granules are released.

The main growth factors detected in PRGF formulations are: transforming growth factor (TGF $\beta 1$ ), vascular endothelial growth factor (VEGF), insulin-like growth factor (IGF-1), and platelet-derived growth factor (PDGR). Additionally, the cytokines and chemokines involved in the healing process and immunomodulatory pathway, namely interleukin (IL-1 $\beta$, IL-8), monocyte chemotactic proteins (MCP-1, MCP-2 and MCP-3), and normal T cell (RANTES), can be quantified in activated PRGF. The quality of PRGF formulations depends on the preparation methodologies and can be assessed by quantification of these therapeutic molecules. The regulation and kinetic release of all these multiple growth factors may require, in some therapeutic conditions, their association or incorporation into biomaterials or drug delivery systems.

By using these concepts, the aim of our study was to evaluate the properties of modified collagen membranes by incorporation of PRGF into different types of commercial collagen membranes, and to investigate the resulting structural and morphological details and mechanical properties. A significant view of the mechanical behavior at nanoscale will be a valuable approach in providing clinicians with as much data as possible to help them in a successful comparison and, at the same time, to a better selection with respect to their placement and working condition [14].

The performances of modified membranes were assessed in a comparative study, by attenuated total reflection (ATR) Fourier transform infrared (FTIR) spectroscopy, nanoindentation, atomic force microscopy (AFM) and scanning electron microscopy (SEM), starting from different commercially available collagen membranes.

\section{Materials and Methods}

\subsection{Preparation of Plasma Rich in Growth Factors (PRGF), Hematology Parameters, and Growth Factor Content}

PRGF was prepared according to a method described by Anitua et al. [17,18]. The blood was withdrawn from the cephalic vein of a healthy volunteer (male, age 45, originated from Bihor County, Romania, previously informed about the purpose of the procedure), in two sterile test tubes, $9 \mathrm{~mL}$ each, 
containing $0.4 \mathrm{~mL}$ of $3.8 \%$ sodium citrate solution as an anticoagulant. The tubes were centrifuged at $580 \mathrm{G}$ for 8 minutes at room temperature. The blood was thus separated into its three basic components: 1) red blood cells, which appeared at the bottom of the tube; 2 ) leukocytes, as a thin layer above the erythrocytes; and 3) plasma, above the white cells. PRGF (fraction 2) is represented by the first $2 \mathrm{~mL}$ of plasma located above the white cells. The PRGF fraction from each tube was carefully collected and transferred to sterile graduated tubes ( $1.3 \mathrm{~mL}$ of PRGF in each tube), and then $50 \mu \mathrm{L}$ of $10 \%$ calcium chloride was added to PRGF. After an activation time of 15 minutes, the PRGF gel was formed and ready to be used in combination with collagen membranes. In order to characterize the quality of collected PRGF, the platelet, erythrocyte, and leukocyte concentration was assessed by using a hematology analyzer (Micros 60, Horiba ABX, Montpellier, France). Additionally, the amounts of several key growth factors were quantified immediately after preparation, by commercially available enzyme-linked immunosorbent assay kits (DSX ${ }^{\circledR}$ —Dynex Technologies Inc. Denkendorf, Germany). The selected growth factors and cytokines/chemokines quantified for this study were: TGF- $\beta 1$, VEGF, IGF-1, PDGR, RANTES, IL-1 $\beta$, and MCP-1.

\subsection{PRGF Modified Collagen Membranes}

Commercially available collagen membranes were chosen for this experiment: Cova ${ }^{\mathrm{TM}_{\mathrm{M}} \mathrm{Max}}$ (Biotech International, Salon de Provence, France), Jason ${ }^{\circledR}$ (Botiss Biomaterials, Zossen, Germany), and Biocollagen ${ }^{\circledR}$ (Bioteck, Arcugnano, Italy). According to the manufacturer's datasheet, Cova ${ }^{\mathrm{TM}} \mathrm{Max}$ originates from acellular porcine dermis (reticulated collagen) and exhibits a degradation period of about 7 weeks. Biocollagen ${ }^{\circledR}$ membrane is made of collagen from porcine Achilles tendon, and its integrity is sustained for 4-6 weeks. Jason ${ }^{\circledR}$ membrane is produced from porcine pericardium, has a very dense fiber structure, and is completely resorbed within 12 weeks after implantation (according to datasheet). All three types of collagen membrane are completely resorbable, designed to be used in stomatology, maxillo-facial surgery, implantology, periodontology, and oral surgery. The membranes, as supplied from the producers, were soaked in PRGF for the activation time (15 $\mathrm{min})$ and then allowed to completely dry, suspended in clamps. The humidity of each membrane was checked after different time intervals. The membranes were sandwiched between sheets of blotting paper. After 24 hours we considered that all the samples were completely dried.

The percent of PRGF taken up by each membrane was calculated according to the following equation:

$$
\operatorname{PRGF}(\%)=\frac{M_{s}-M_{d}}{M_{d}} \times 100,
$$

where $M_{s}$ and $M_{d}$ are the weight of swollen and dry membrane, respectively.

After complete drying, each sample was cut in four equal pieces $(12.5 \times 7.5 \mathrm{~mm})$ in order to perform Fourier transform infrared (FTIR) spectroscopy, scanning electron microscopy (SEM), atomic force microscopy (AFM), and nanoindentation measurements.

\subsection{FTIR Spectroscopy}

The primary purpose of using FTIR spectroscopy was to investigate any specific interaction between collagen and PRGF components, or any chemical modifications that may have occurred as a result of this interaction. FTIR spectroscopy was carried out using Spectrum BXII spectrophotometer (PerkinElmer, Waltham, MA, USA), equipped with MIRacle ATR accessory (ZnSe crystal), operating in the range $400-4000 \mathrm{~cm}^{-1}$, with a scanning speed of $32 \mathrm{~cm}^{-1}$ and spectral width $2.0 \mathrm{~cm}^{-1}$. A comparison was made between the spectra recorded from the original membranes (as provided from the supplier, no treatment) and the samples modified with PRGF.

\subsection{AFM and SEM Analysis}

AFM was applied in this study aiming to evaluate the topographic details of collagen features in nanoscale, and to compare the properties of single collagen fibers upon PRGF treatment. Its 
major advantage over other microscopic techniques is its ability to offer molecular resolution without special treatment or vacuum conditions. The primary purpose of SEM analysis was to investigate the morphological details of cross-sectioned membranes before and after PRGF treatment, including the pore size and collagen fiber alignment. The surface images of the collagen membranes and fiber details were obtained by using Agilent 5500 AFM. The samples were fixed on glass plates with double-sided tape. The scanning was performed at room temperature and normal humidity level (50\%), in acoustic mode (also known as taping mode), in which the AFM tip oscillates slightly below its resonance frequency $(317.14 \mathrm{kHz})$ and scans the selected area with a speed of $5.361 \mu \mathrm{m} / \mathrm{s}$ at a resolution of $512 \times$ 512 data points, and in contact mode, in which the AFM tip maintains close contact with the surface of the sample while scanning the selected area with a speed of $2.16 \mu \mathrm{m} / \mathrm{s}$ at a resolution of $512 \times 512$ data points, respectively.

The scanning electron microscope device was Leo 438VP SEM, with variable vacuum capability (maintained at low value), obtaining cross-section images of the inner structure of the collagen membranes.

\subsection{Nanoindentation Measurements}

PRGF-modified and original collagen membranes were subjected to mechanical tests using the Nanoindenter G200 device manufactured by Keysight (Agilent Technologies, Santa Clara, CA, USA). The tip used to determine the mechanical properties was a diamond Berkovich, pyramidal shaped tip. The instrument is ISO standardized as XP ISO 14577 standard test method. The membranes were tested at room temperature and normal humidity $(45-52 \%)$. The values of Young modulus were obtained from load-displacement curves, by fitting parameters, using Oliver-Pharr method [22,23].

There were 72 indentation sites distributed in 3 groups of 24, chosen randomly on the surface of each piece; a load-unload displacement curve was generated by pressing the sample with the diamond tip, reaching a maximum of $2000 \mathrm{~nm} / \mathrm{s}$ depth, while recording the forces for the load curve. In the second phase, the force was slowly decreased by $90 \%$, allowing the material to push back and reduce the depth of the deformation, resulting in the unload curve. Using the data from the load curve generated, the hardness of the sample can be calculated using the formula:

$$
H=\frac{P_{\max }}{A_{c}},
$$

where $P_{\max }$ represents the applied maximum load, and $A_{c}$ is the horizontal projection of the contact area of the tip at the end of the loading phase. In the case of the Berkovich pyramidal shape, $A_{c}=24.5$ $h^{2}, h$ being the depth. Using the data from the second phase (the unloading phase), Young modulus was calculated by determining the stiffness $(S)$ from the initial slope:

$$
S=\left(\frac{\partial P}{\partial h}\right)_{\max }
$$

and consequently, the reduced elastic modulus:

$$
E_{r}=S \frac{\sqrt{\pi}}{2 A_{c}}
$$

Finally, the Young modulus was determined using the equation:

$$
E_{r}=\frac{E}{\left(1-v^{2}\right)}
$$

where $v=0.3$ is the Poisson's ratio of the samples. 


\subsection{Enzymatic Degradation Test}

Five specimens from the native membranes (as supplied from the manufacturer) and five from each PRGF-modified membrane, were cut into squares $\left(15 \times 15 \mathrm{~mm}^{2}\right)$ and weighted. Then, the specimens were immersed in a $0.25 \%$ trypsin solution (porcine trypsin, Sigma-Aldrich, Steinheim, Germany) and incubated at $37^{\circ} \mathrm{C}$ (Model MCO-5 AC, Sanyo/Panasonic Biomedical, York, GB) under a flux of $5 \% \mathrm{CO}_{2}$. After different time intervals $(9,18,36$, and 72 hours), the specimens were carefully removed, one by one, and allowed to completely dry in order to measure their weight. The membranes were sandwiched between sheets of blotting paper in order to check if dried completely. The weight of the remaining mass was expressed as percentage (mean value $\pm \mathrm{SD}$ ) and the statistical significance was measured by ANOVA test. A $p$ value of less than 0.05 was considered significant.

\section{Results}

\subsection{Preparation of Plasma Rich in Growth Factors (PRGF), Hematology Parameters, and Growth Factor Content}

The separation of plasma components upon centrifugation and subsequent PRGF (fraction 3) separation by pipetting, followed by immersion of membranes in PRGF, is represented in Figure 1a-c. The hematological parameters were determined in whole blood and PRGF fraction by hematology analyzer and presented comparatively in Table 1. In order to assess the quality of PRGF, the expression level of the main growth factors are presented in Table 2. Quantitative data in both tables are expressed as mean \pm standard deviation.

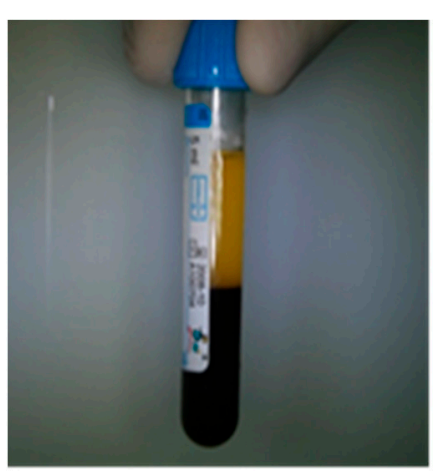

(a)

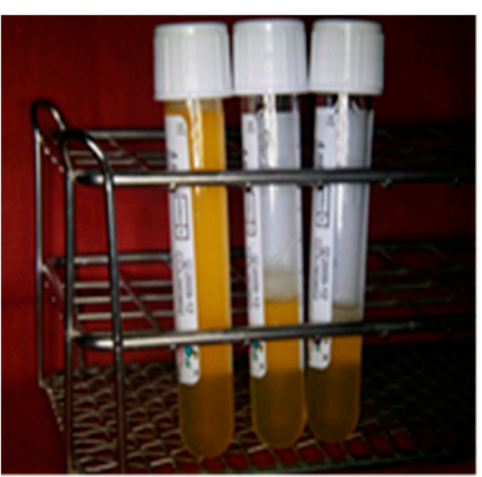

(b)

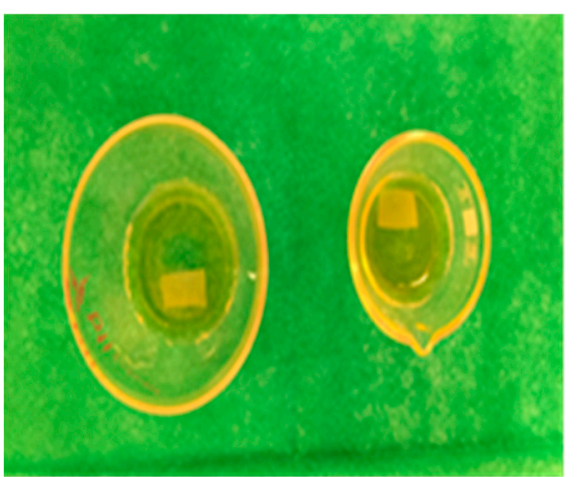

(c)

Figure 1. Whole blood separation upon centrifugation at $580 \mathrm{G}$ for 8 minutes at room temperature (a) and subsequent platelets rich in growth factor (PRGF) separation by pipetting (b); membrane immersion in PRGF (c).

Table 1. Hematology parameters of whole blood and PRGF fraction.

\begin{tabular}{lll}
\hline \multicolumn{1}{c}{ Component } & Whole Blood/Normal Range & PRGF \\
\hline Leukocytes $\left(\times 10^{-3} / \mu \mathrm{L}\right)$ & $5.9 \pm 0.2 / 4-10$ & $0.4 \pm 0.1$ \\
Erythrocytes $\left(\times 10^{-6} / \mu \mathrm{L}\right)$ & $4.5 \pm 0.4 / 3.8-5$ & $0.01 \pm 0.01$ \\
Platelets $\left(\times 10^{-3} / \mu \mathrm{L}\right)$ & $210 \pm 20 / 150-300$ & $655 \pm 85$ \\
\hline
\end{tabular}

The percent of PRGF uptaken by the different commercial collagen membrane was $190 \%$ for Biocollagen ${ }^{\circledR}, 154 \%$ for Cova ${ }^{\mathrm{TM}}$ Max, and $150 \%$ for Jason ${ }^{\circledR}$ membrane.

\subsection{Characterization of PRGF-Modified Collagen Membranes by FTIR Spectroscopy}

ATR FTIR spectra of commercial collagen membranes before and after immersion in PRGF are presented in Figure 2. The vibrational details of the spectra revealed the fingerprints of collagen as an intact triple helix conformation: amide I at $1630 \mathrm{~cm}^{-1}$ (C=O stretching), amide II at $1580 \mathrm{~cm}^{-1}$ (N-H in 
plane deformation and C-N stretching), and amide III at $1235 \mathrm{~cm}^{-1}$ (C-N stretching and N-H bending vibration from amide linkages). These fingerprints were very well preserved after PRGF treatment, which demonstrates that no specific interaction between collagen and PRGF components occurred [24].

Table 2. Quantitative assessment of the main growth factors, cytokines, and chemokines in PRGF fraction.

\begin{tabular}{ll}
\hline \multicolumn{1}{c}{ Growth Factor Content } & Value \\
\hline $\begin{array}{l}\text { Transforming growth factor TGF } \beta 1 — \text { enhances the proliferative activity of fibroblasts and } \\
\text { stimulates the biosynthesis of collagen and fibronectin }\end{array}$ & $43 \mathrm{ng} / \mathrm{mL} \pm 8.2$ \\
$\begin{array}{l}\text { Vascular endothelial growth factor VEGF—induces angiogenesis via migrating endothelial cells } \\
\text { Insulin-like growth factor IGF-1—a primary mediator of the effects of growth hormone; can also }\end{array}$ & $220 \mathrm{pg} / \mathrm{mL} \pm 20$ \\
regulate cellular DNA synthesis & $105 \mathrm{ng} / \mathrm{mL} \pm 15.5$ \\
$\begin{array}{l}\text { Platelet-derived growth factor PDGR—enhances collagen synthesis and bone cell proliferation } \\
\text { RANTES chemokine (CCL5)—role in regulating T-cell responses and immunity during chronic }\end{array}$ & $14 \mathrm{ng} / \mathrm{mL} \pm 3.5$ \\
$\begin{array}{l}\text { and acute infection } \\
\text { Interleukin IL-1 } \beta \text { cytokine—regulates and initiates inflammatory responses }\end{array}$ & $400 \mathrm{pg} / \mathrm{mL} \pm 100$ \\
$\begin{array}{l}\text { Monocyte chemotactic proteins (MCP-1)—regulates the expression of cell surface antigens; can } \\
\text { induce the proliferation and activation of killer cells }\end{array}$ & $20 \mathrm{pg} / \mathrm{mL} \pm 5.0$ \\
\hline
\end{tabular}

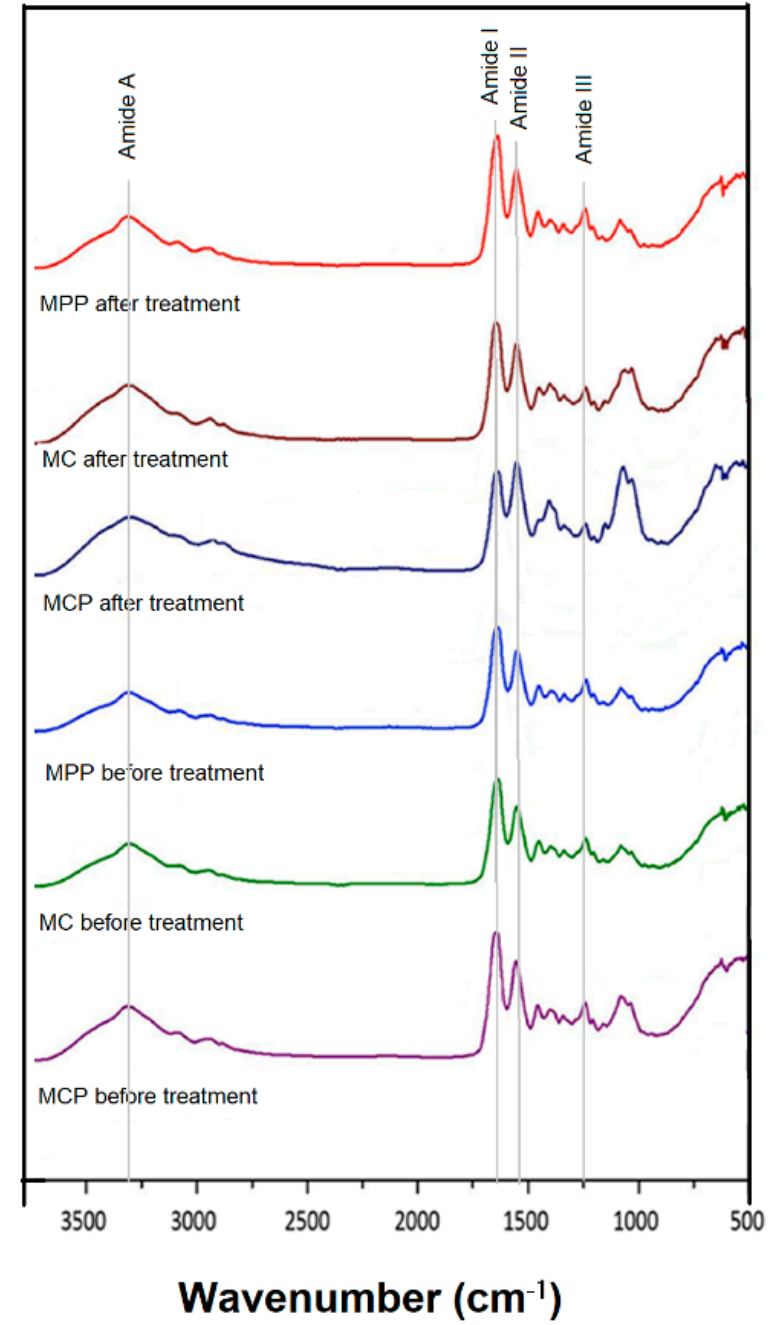

Figure 2. ATR FTIR (Attenuated Total Reflection Fourier Transform Infrared) spectra of commercial collagen membranes for bone-guided regeneration before and after PRGF treatment. Legend: Biocollagen $^{\circledR}=\mathrm{MCP} ;$ Cova $^{\mathrm{TM}}$ Max $=$ MPP; Jason $^{\circledR}=$ MC. 


\subsection{Morphological Characterization by SEM and AFM}

In Figure 3, the electron microscopy images of the cross-sectioned collagen membranes before $(\mathrm{a}, \mathrm{d}, \mathrm{g})$ and after $(\mathrm{b}, \mathrm{e}, \mathrm{h})$ PRGF treatment are presented, along with the topographic details of the surface $(\mathrm{c}, \mathrm{f}, \mathrm{i})$.
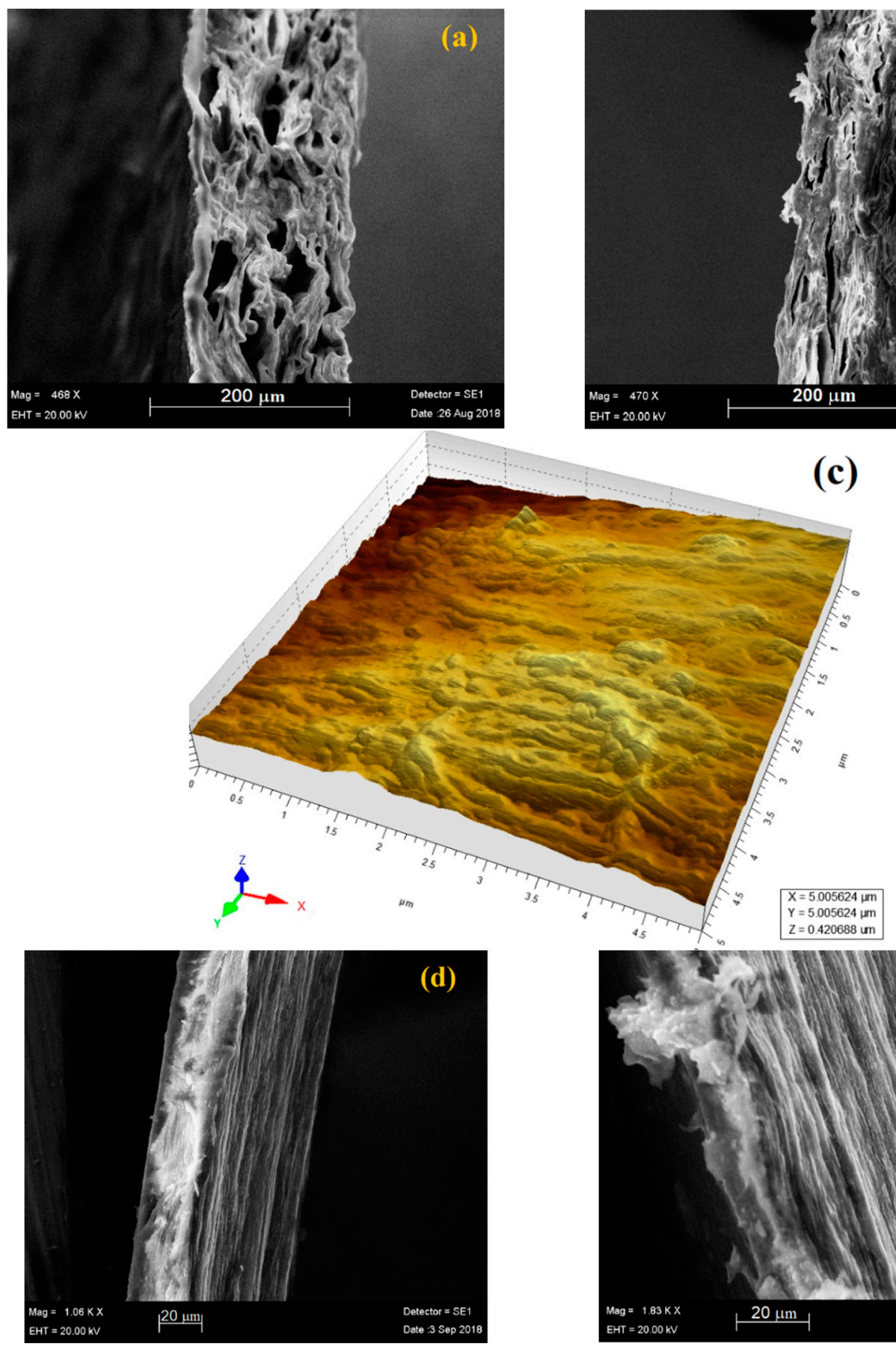

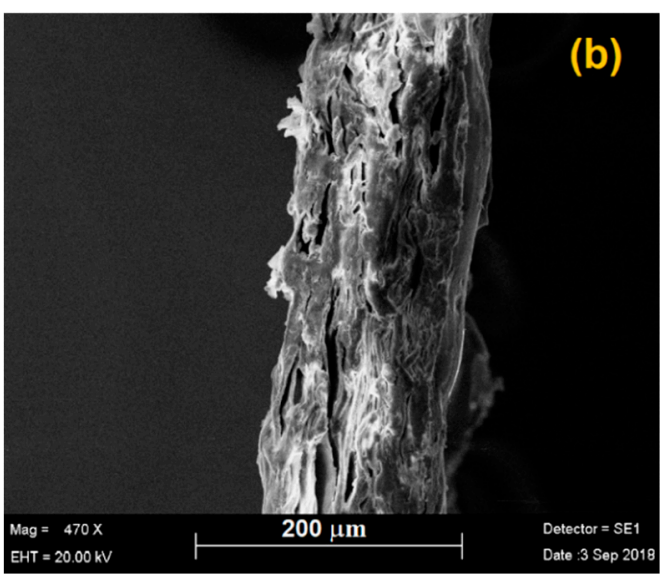

(c)

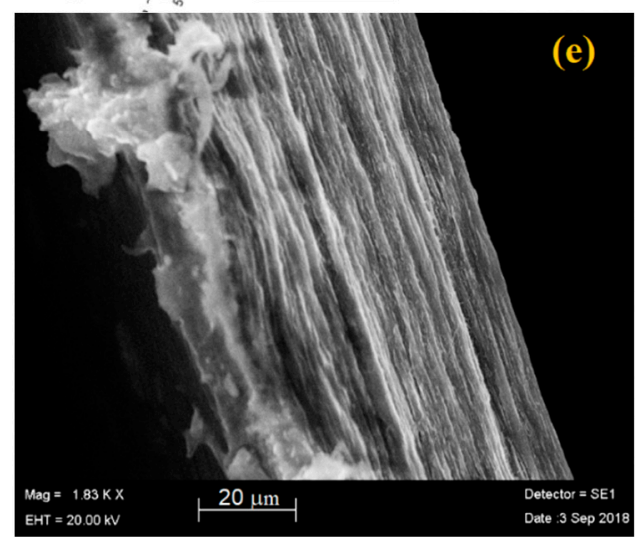

Figure 3. Cont. 


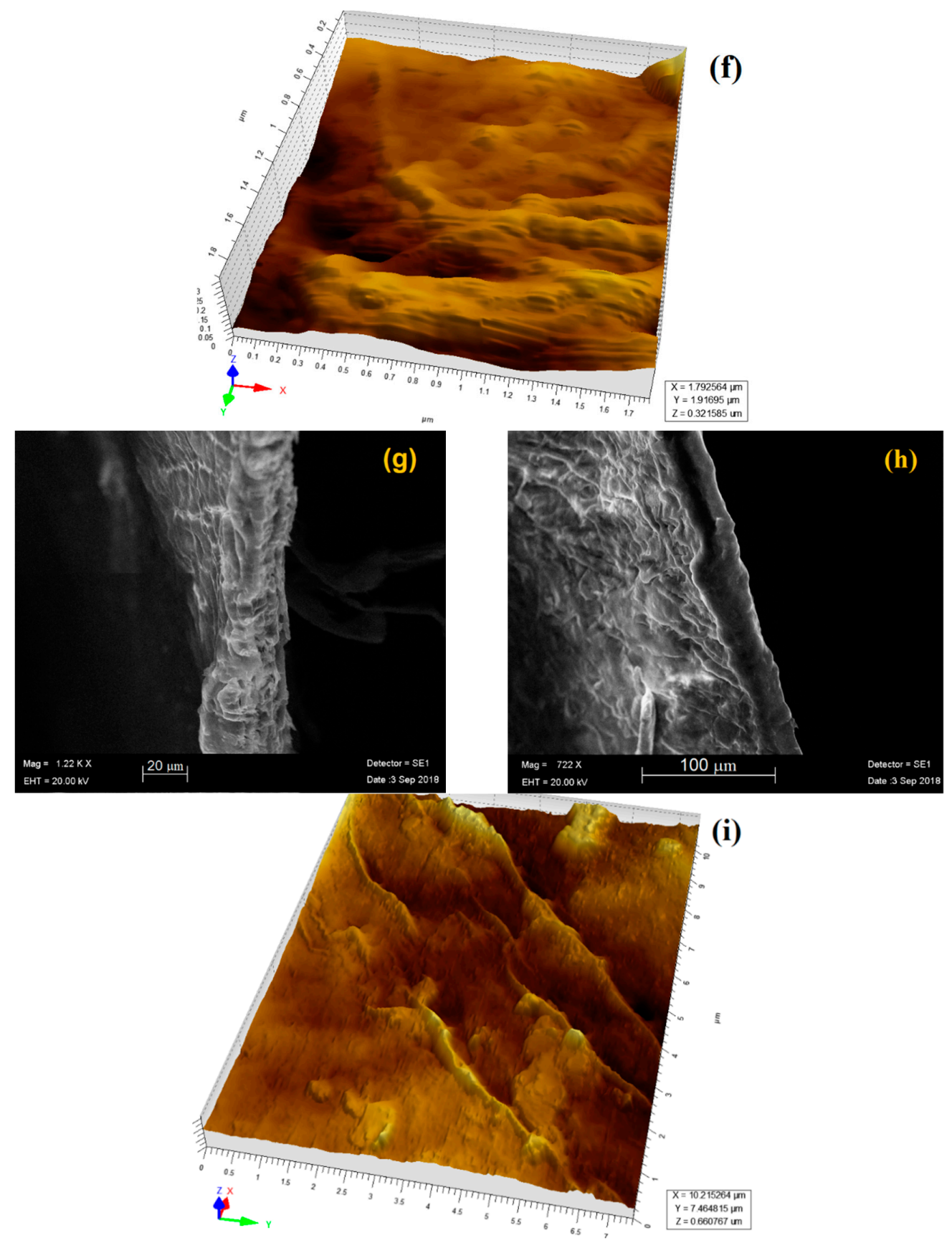

Figure 3. Cross-sectional scanning electron microscopy (SEM) images of different commercial collagen membranes before $(\mathbf{a}, \mathbf{d}, \mathbf{g})$ and after $(\mathbf{b}, \mathbf{e}, \mathbf{h})$ PRGF treatment; AFM 3D topography of the membrane surface after PRGF treatment $(\mathbf{c}, \mathbf{f}, \mathbf{i})$ showing the details of collagen fibers. The images correspond to Biocollagen $^{\circledR}(\mathbf{a}-\mathbf{c})$, Cova $^{\mathrm{TM}} \operatorname{Max}(\mathbf{d}-\mathbf{f})$, and Jason ${ }^{\circledR}(\mathbf{g}-\mathbf{i})$.

Comparing the morphological details, one can observe a very different ultrastructure between the three membranes. A porous structure (pore size approximatively $40 \mu \mathrm{m}$ ), with a network of collagen fiber bundles, quasi-orientated, was noticed for Biocollagen ${ }^{\circledR}$. It seems that after PRGF treatment, this structure became more compact, while the porosity was significantly reduced. The SEM images were recorded from three different sites of the membrane. The average pore size was determined by scaling the diameter of five different pores in each image.

The cross-section of Cova ${ }^{\mathrm{TM}}$ Max revealed a very dense and compact structure, with well-aligned collagen fibers in a multilayered lamellar structure, which was preserved after PRGF treatment. Apparently, a smooth surface can be noticed in this case. As for Jason ${ }^{\circledR}$ membrane, a dense structure 
with differently orientated collagen fibers providing a multi-directional network was noticed. A rough surface with well-defined collagen fibers can be observed. This microstructure was also preserved after PRGF treatment. The topographic aspects observed in AFM images revealed the details of collagen fibers with diameters ranging between 150-200 nm. The diameter of collagen fibers was determined by recording the height profile of the selected area. As a general behavior, after PRGF treatment, the diameter of collagen fibers slightly increased (by approximatively $20 \mathrm{~nm}$ ) in all the three cases (AFM images before treatment are not shown here).

\subsection{Nanoindentation Measurements}

Load-displacement curves were recorded for each membrane before and after PRGF treatment and presented comparatively in Figure 4. According to the load-displacement profiles, in the case of Jason ${ }^{\circledR}$ membrane, a slight increase occurred for each applied load to reach the same indentation, when the membrane was treated with PRGF (Figure 4a-b). A significant modification occurred in the case of Biocollagen ${ }^{\circledR}$ membrane, as almost double the applied load was required in order to reach the same indentation (Figure $4 \mathrm{c}-\mathrm{d}$ ). With respect to Cova ${ }^{\mathrm{TM}}$ Max membrane, a slight decrease of the applied load was necessary to get the same indentation (Figure $4 \mathrm{e}-\mathrm{f}$ ).

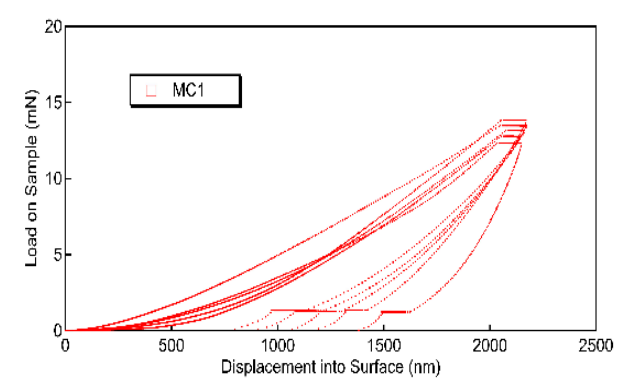

(a)

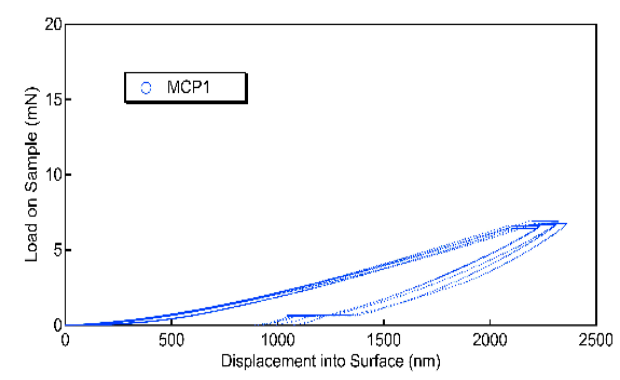

(c)

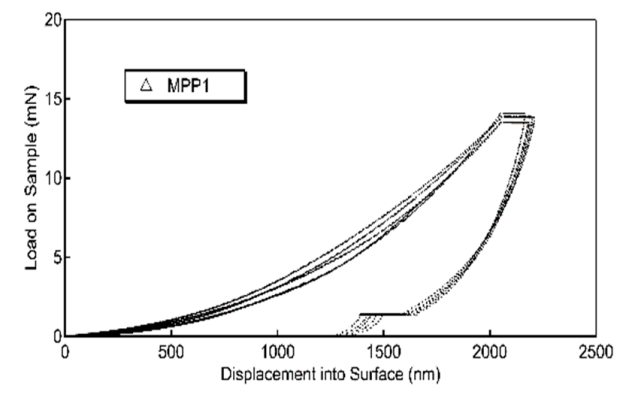

(e)

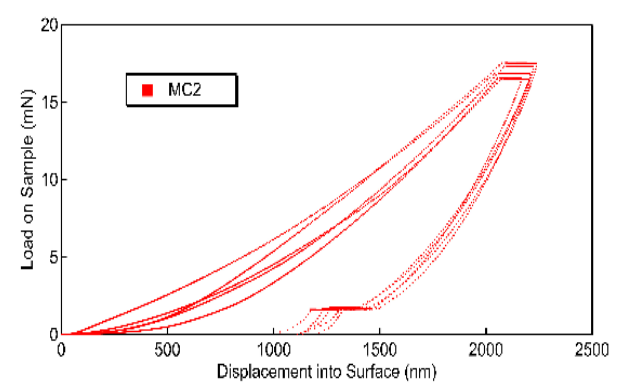

(b)

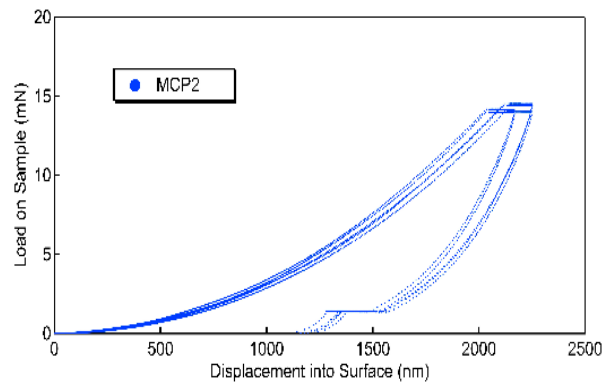

(d)

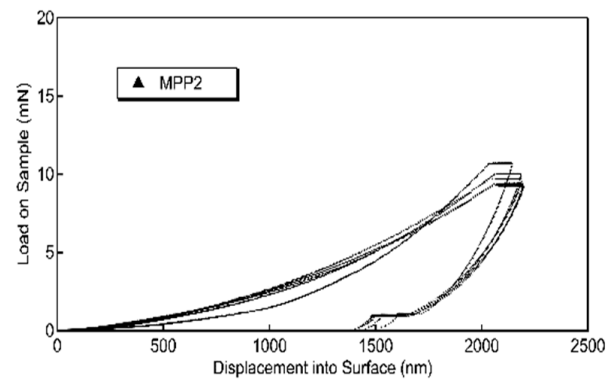

(f)

Figure 4. Nanoindentation measurements: load-displacement curves recorded for each membrane before $(\mathbf{a}, \mathbf{c}, \mathbf{e})$ and after $(\mathbf{b}, \mathbf{d}, \mathbf{f})$ PRGF treatment. The images correspond to Jason ${ }^{\circledR}(\mathbf{a}, \mathbf{b})$, Biocollagen ${ }^{\circledR}$ $(\mathbf{c}, \mathbf{d})$, and Cova ${ }^{\mathrm{TM}} \mathrm{Max}(\mathbf{e}, \mathbf{f})$. Legend: $\mathrm{MC} 1 / \mathrm{MC} 2=\mathrm{Jason}^{\circledR}$ membrane before/after PRGF treatment; $\mathrm{MCP} 1 / \mathrm{MCP} 2=$ Biocollagen $^{\circledR}$ membrane before/after PRGF treatment; MPP1 $/ \mathrm{MPP} 2=\mathrm{Cova}^{\mathrm{TM}} \mathrm{Max}$ membrane before/after PRGF treatment. 
Comparing the data related to the non-treated membranes, one can observe good fitting results, with low scattering data, in the case of Cova ${ }^{\mathrm{TM}} \mathrm{Max}$, as revealed in Figure 5. This type of membrane also exhibited higher stiffness $(E=4 \mathrm{GPa})$, while Biocollagen ${ }^{\circledR}$ was the softest one by comparison $(E=1 \mathrm{GPa})$. However, after the PRGF treatment, a significant increase in Young modulus value was observed for Biocollagen ${ }^{\circledR}$, a moderate increase for Jason ${ }^{\circledR}$, and a small decrease for Cova ${ }^{\mathrm{TM}}$ Max. Overall, after the PRGF treatment, the nanoindentation measurements indicated the Young modulus value ranging in the interval 2.8-4 GPa in all the cases (Figure 5).

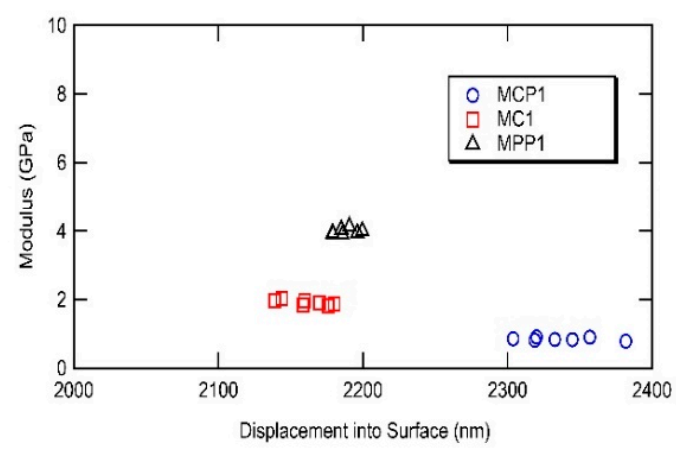

(a)

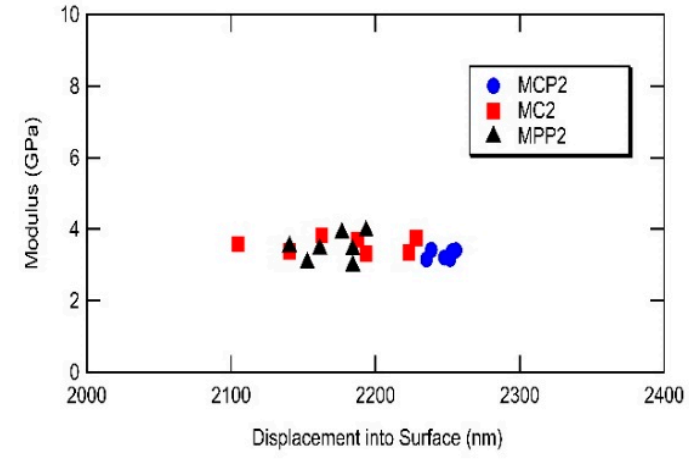

(b)

Figure 5. Young modulus calculations with respect to the three collagen membranes before (a) and after PRGF treatment $(\mathbf{b})$. Legend: MPP1/MPP2 = Cova ${ }^{\mathrm{TM}}$ Max membrane before/after PRGF treatment; $\mathrm{MC} 1 / \mathrm{MC} 2=$ Jason $^{\circledR}$ membrane before/after PRGF treatment; $\mathrm{MCP} 1 / \mathrm{MCP} 2=$ Biocollagen $^{\circledR}$ membrane before/after PRGF treatment.

\subsection{Enzymatic Degradation}

Figure 6 presents the diagram corresponding to enzymatic (trypsin) degradation of native (unmodified) membranes compared to PRGF-modified collagen membranes, monitored during the $72 \mathrm{~h}$ incubation time. Within the first 9 hours, only a small degradation was noticed for all the specimens. By comparing the results at each specific incubation time $(9,18,36$, and $72 \mathrm{~h})$, the diagram reveals that PRGF-modified membranes exhibited a slower degradation compared with the native ones, in all the three cases. After the first 9 hours, only a small degradation was noticed in all the three cases, but the degradation occurred gradually during the entire interval (72 hours). The highest degradation rate was noticed for Biocollagen ${ }^{\circledR}$. Jason ${ }^{\circledR}$ had a moderate degradation rate, and Cova ${ }^{\mathrm{TM}}$ Max had a slow one. This effect was even more evident after $72 \mathrm{~h}$, in the case of unmodified Biocollagen ${ }^{\circledR}$, exhibiting more than $50 \%$ degradation. Overall, a significant difference between the three membranes was observed during the enzymatic degradation process $(p<0.05)$. 


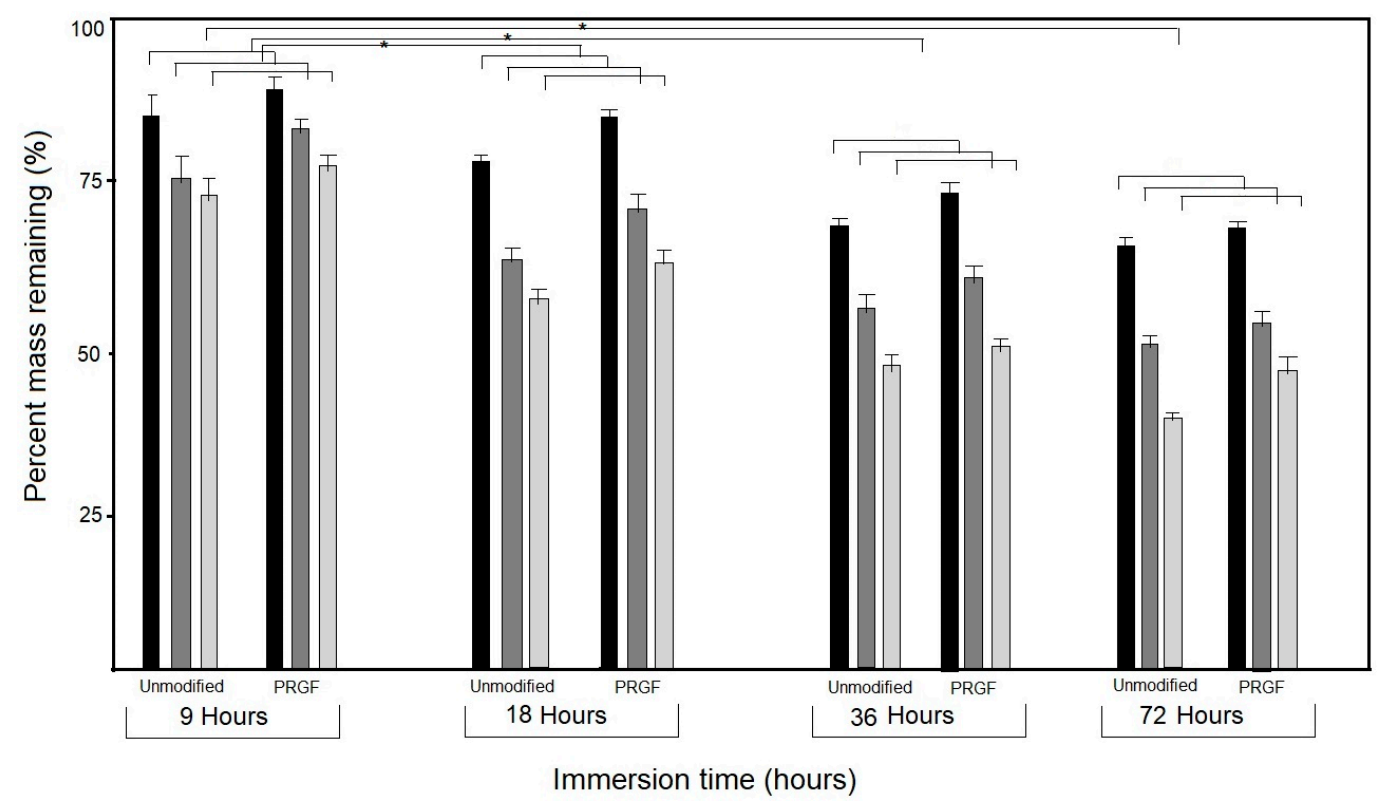

Figure 6. Results of enzymatic degradation test of native (unmodified) and PRGF-modified collagen membranes. Legend: Cova $^{\mathrm{TM}}$ Max; $\square$ Jason ${ }^{\circledR} ; \square$ Biocollagen ${ }^{\circledR}$.

\section{Discussion}

Due to their advantages in terms of their different degrees of biodegradability, resorbable membranes, especially collagen-type, are the most popular in the field of dentistry, maxillo-facial surgery, or regeneration medicine [25]. It is very difficult to compare collagen membranes in terms of their resorbability and biodegradability based exclusively on the information reported in their datasheets, as it refers to different processing conditions and provenience. Crosslinking techniques and decellularization approaches may have different influences on the mechanical, biological, and chemical properties of treated tissues [26].

Previous studies demonstrated that different types of natural polymeric membranes can serve not only as scaffolds but also as good candidates for localized delivery of morphogenetic proteins [27]. On the other hand, the concept of PRGF and its related mechanism is that by increasing the concentration of growth factors and cytokines that are released by platelets, the healing process is accelerated [28]. The actual definition of protein rich plasma (PRP) (and related PRGF) is accepted as a minimum platelet concentration three times that of whole blood $[18,19,29]$. In our study, as presented in Table 1, the counted platelets are in agreement with this definition. Moreover, the main growth factor levels and cytokines were quantitatively assessed (Table 2). The values presented in Table 2 are in agreement with previously reported data [19,29-33]. These previous results demonstrated that different plasma formulations enhance proliferation and migration of fibroblast populations, protect and inhibit TGF-1-induced myofibroblast differentiation, and regulate the metabolic activity of mesenchymal stem cells [33]. However, different PRGF formulations reported in the literature, prepared by various methodologies, consist of completely different compositions in terms of growth factors and cytokine concentrations, which may result in different therapeutic effects. Centrifugation conditions are fundamental to obtain a high PRP quality, together with quantification and identification of platelets and lymphocytes. For example, Anitua et al. [18] consider that inclusion of leukocytes may induce pro-inflammatory effects of the proteases and acid hydrolases contained in white blood cells, while other authors claim that these details are not important.

The FTIR spectra recorded on both PRGF-modified and unmodified membranes demonstrated that there is no specific interaction between collagen and PRGF components, as the fingerprints of collagen molecules are very well preserved upon PRGF-loading in all the three cases. No denaturation 
or chemical modification were detected, according to Figure 2, so the collagen matrix may act as a natural reservoir for growth factor delivery.

The cross-sectional images obtained by SEM revealed different ultrastructural details with respect to the three types of membrane selected for this study. This ultrastructure was preserved after PRGF-loading, except for Biocollagen ${ }^{\circledR}$, in which the porosity seemed to decrease, resulting in a more compact structure. According to the literature, natural biopolymers with porous structures (pore size $>25 \mu \mathrm{m}$ ) are well-known for their excellent biological functions, demonstrating better bone formation during the initial healing period than non-porous membranes [25,34]. On the other hand, a more effective cell attachment and differentiation is achieved with nano-sized pores, while micro-sized pores are able to improve angiogenesis and nutrients transport, favoring the mineral deposits [25,35].

By AFM investigation, we were able to emphasize the details of collagen fibers on the surface, especially their orientation and thickness. As compared with the literature, fiber thickness is less than that of collagen fibers in thin films created by spin coating methods [36,37]. By this technique, thin films consisting of randomly-oriented collagen fibrils were obtained, with the diameter varying from $300 \mathrm{~nm}$ up to $700 \mathrm{~nm}$. The surface topography may play an important role in cellular response to collagen $[38,39]$.

According to the literature, the Young modulus (average value) of a single collagen type 1 fiber is between 1.2-2 GPa [36], as the mechanical strength of a single collagen fiber is due to hydrogen bonds that stabilize the triple helix within the collagen molecules. In the case of a membrane, which is formed by a network of crosslinked collagen fibers, higher Young modulus values are expected. Different values of Young modulus, related to each manufacturer, can be correlated to the typically required chemical or physical pretreatment, aiming to preserve and sterilize the tissue. These treatments include chemical, enzymatic, or mechanical decellularization techniques in order to remove cellular components $[26,40]$. The resulting acellular tissue may retain, to a certain extent, the natural mechanical properties and promote tissue remodeling by neovascularization and recellularization.

These aspects could be responsible for the relatively high scattering of data in the case of Biocollagen ${ }^{\circledR}$ and Jason ${ }^{\circledR}$, compared with Cova ${ }^{\mathrm{TM}}$ Max, before PRGF treatment. On the other hand, upon PRGF treatment, the changes of Young modulus values could be correlated with the ultrastructural properties of each membrane type, especially the porosity. The higher the porosity, the lower the Young modulus value obtained, which is consistent with similar results previously reported in literature [25]. This is also the reason why, after PRGF treatment, the Young modulus values are displayed in a narrow interval (2.8-4 GPa), compared with the corresponding values before treatment. Also, according to the literature, it has been demonstrated that as the collagen concentration or density is increased, the tissue becomes stiffer, and because of this, cells behave differently at different collagen concentrations [41]. Therefore, because the Young modulus is correlated with collagen density modifications, at physiological rate, the cells can sense this difference.

The enzymatic (trypsin) degradation test also emphasized different behaviors of the membranes with or without PRGF treatment. As a general behavior, PRGF-modified membranes exhibited a slower degradation compared with the native ones, in all the three cases.

The differences observed for the native membranes can be explained by the cross-linking techniques used by the manufacturers, as any cross-linking technique may have uncertain effects on the structure of collagen membrane [42].

On the other hand, the trypsin treatment also caused a time-dependent release of water-soluble proteins; the disaggregation of collagen fibrils occurs as a consequence of the degradation of proteoglycan bridges between collagen fibrils. Previous results indicated that in the case of trypsin-treated collagen fibers (over $72 \mathrm{~h}$ ), the collagen fibrils still kept their structural integrity by retaining their triple-helical conformation [43]. Yin-Zhe et al. [42] previously reported that higher collagen density and compact structure may be a reason of slower biodegradation. However, further studies are required in order to assess whether the results obtained in our study can be applied to humans, as the local environment in the oral cavity is a complex biochemical "reactor" difficult 
to mimic. The present study was only limited to structural and mechanical characterization of the commercial collagen membranes incorporating PRGF factors. Our next approach will be focused on the biological performance of these membranes, performing in vitro assays to evaluate the cellular adhesion, proliferation, and viability of human osteoblasts, fibroblasts, and keratocytes.

\section{Conclusions}

PRGF-modified collagen membranes investigated in our study present new evidence of several advantages, with respect to a rapid and predictable soft tissue healing. The structural and morphological features of three different commercial collagen membranes for GBG/GTR were investigated upon PRGF treatment, revealing that particular characteristics such as porosity, fiber density, and surface topography may influence the mechanical behavior and performance of the membranes. By FTIR spectroscopy, it was demonstrated that the collagen matrix may act as a natural reservoir for growth factor delivery. Nanoindentation measurements revealed that, upon PRGF treatment, the changes of Young modulus values are correlated with the ultrastructural properties of each membrane type, especially the porosity. The mechanical properties of the membranes were analyzed in a comparative manner, before and after PRGF modification. The enzymatic (trypsin) degradation test also emphasized a different behavior-PRGF-modified membranes exhibited a slower degradation compared with the native ones. Within the limitations of the present study, the results are important with respect to the regulation and kinetic release of multiple growth factors that can be adapted to specific therapeutic conditions.

Author Contributions: Conceptualization: C.R. and M.B.; investigation: T.C., L.M. and S.C.; methodology: C.R., M.B. and S.C.; software: T.C. and L.M.; supervision: S.C.; validation: T.C. and L.M.; writing-original draft: C.R. and M.B.; writing一review \& editing: S.C.

Funding: This research received no external funding.

Conflicts of Interest: The authors declare no conflict of interest.

\section{References}

1. Rakhmatia, Y.D.; Ayukawa, Y.; Furuhashi, A.; Koyano, K. Current barrier membranes: Titanium mesh and other membranes for guided bone regeneration in dental applications. J. Prosthodont. Res. 2013, 57, 3-14. [CrossRef] [PubMed]

2. Jo, Y.-Y.; Oh, J.-H. New resorbable membrane materials for guided bone regeneration. Appl. Sci. 2018, 8, 2157. [CrossRef]

3. Choi, N.-R.; Sándor, G.K.; Kim, Y.D. Efficacy of collagen-based membranes in alveolar bone augmentation. Appl. Sci. 2018, 8, 2048. [CrossRef]

4. Scantlebury, T.V. 1982-1992: A decade of technology development for guided tissue regeneration. J. Periodontol. 1993, 64, 1129-1137. [CrossRef] [PubMed]

5. Hardwick, R.; Scantlebury, T.V.; Sanchez, R.; Whitley, N.; Ambruster, J. Membrane design criteria for guided bone regeneration of the alveolar ridge. In Guided Bone Regeneration in Implant Dentistry; Buser, D., Ed.; Quintessence Publishing Co. Inc.: Batavia, IL, USA, 1994; pp. 101-136.

6. Monteiro, A.S.; Macedo, L.G.; Macedo, N.L.; Balducci, I. Polyurethane and PTFE membranes for guided bone regeneration: Histopathological and ultrastructural evaluation. Med. Oral Patol. Oral Cir. Bucal. 2010, 15, e401-e406. [CrossRef] [PubMed]

7. Zhang, J.; Xu, Q.; Huang, C.; Mo, A.; Li, J.; Zuo, Y. Biological properties of an anti-bacterial membrane for guided bone regeneration: An experimental study in rats. Clin. Oral Implants Res. 2010, 21, 321-327. [CrossRef] [PubMed]

8. McGinnis, M.; Larsen, P.; Miloro, M.; Beck, M. Comparison of resorbable and nonresorbable guided bone regeneration materials: A preliminary study. Int. J. Oral Maxillofac. Implants 1998, 13, 30-35. [PubMed]

9. Jung, R.E.; Fenner, N.; Hämmerle, C.H.; Zitzmann, N.U. Long-term outcome of implants placed with guided bone regeneration (GBR) using resorbable and non-resorbable membranes after 12-14 years. Clin. Oral Implants Res. 2013, 24, 1065-1073. [CrossRef] [PubMed] 
10. Kasaj, A.; Reichert, C.; Götz, H.; Röhrig, B.; Smeets, R.; Willershausen, B. In vitro evaluation of various bioabsorbable and nonresorbable barrier membranes for guided tissue regeneration. Head Face Med. 2008, 14, 4-22. [CrossRef] [PubMed]

11. Rothamel, D.; Schwarz, F.; Fienitz, T.; Smeets, R.; Dreiseidler, T.; Ritter, L.; Happe, A.; Zöller, J. Biocompatibility and biodegradation of a native porcine pericardium membrane: Results of in vitro and in vivo examinations. Int. J. Oral Maxillofac. Implants 2012, 27, 146-154. [PubMed]

12. Lee, C.H.; Singla, A.; Lee, Y. Biomedical applications of collagen. Int. J. Pharm. 2001, 221, 1-22. [CrossRef]

13. Kadler, K.E.; Baldock, C.; Bella, J.; Boot-Handford, R.P. Collagen at a glance. J. Cell Sci. 2007, 120, $1955-1958$. [CrossRef] [PubMed]

14. Ortolani, E.; Quadrini, F.; Bellisario, D.; Santo, L.; Polimeni, A.; Santarsiero, A. Mechanical qualification of collagen membrane used in dentistry. Annali dell'Istituto Superiore di Sanità 2015, 51, 229-235. [PubMed]

15. Shoulders, M.D.; Raines, R.T. Collagen structure and stability. Annu. Rev. Biochem. 2009, 78, 929-958. [CrossRef] [PubMed]

16. Bottino, M.C.; Thomas, V.; Schmidt, G.; Vohra, Y.K.; Chua, T.-M.G.; Kowolikd, M.J.; Janowskie, G.M. Recent advances in the development of GTR/GBR membranes for periodontal regeneration. A materials perspective. Dent. Mater. 2012, 28, 703-721. [CrossRef] [PubMed]

17. Anitua, E.; Prado, R.; Troya, M.; Zalduendo, M.; De la Fuente, M.; Pino, A.; Muruzabal, F.; Orive, G. Implementation of a more physiological plasma rich in growth factor (PRGF) protocol: Anticoagulant removal and reduction in activator concentration. Platelets 2016, 27, 459-466. [CrossRef]

18. Anitua, E.; Sanchez, M.; Orive, G.; Andia, I. The potential impact of the preparation rich in growth factors (PRGF) in different medical fields. Biomaterials 2007, 28, 4551-4560. [CrossRef] [PubMed]

19. Anitua, E.; Pino, A.; Jaen, P.; Orive, G. Plasma Rich in Growth Factors enhances wound healing and protects from photo-oxidative stress in dermal fibroblasts and 3D skin models. Curr. Pharm. Biotechnol. 2016, 17, 556-570. [CrossRef] [PubMed]

20. Anitua, E. Plasma Rich in Growth Factors: Preliminary Results of Use in the Preparation of Future Sites for Implants. Int. J. Oral Maxillofac. Implants 1999, 14, 529-535. [PubMed]

21. Nishiyama, K.; Okudera, T.; Watanabe, T.; Isobe, K.; Suzuki, M.; Masuki, H.; Okudera, H.; Uematsu, K.; Nakata, K.; Kawase, T. Basic characteristics of plasma rich in growth factors (PRGF): Blood cell components and biological effects. Clin. Exp. Dent. Res. 2016, 18, 96-103. [CrossRef] [PubMed]

22. Oliver, W.C.; Pharr, G.M. An improved technique for determining hardness and elastic modulus using load and displacement sensing indentation experiments. J. Mater. Res. 1992, 7, 1564-1583. [CrossRef]

23. Pharr, G.; Oliver, W.C.; Brotzen, F. On the generality of the relationship among contact stiffness, contact area and elastic modulus during indentation. J. Mater. Res. 1992, 7, 613-617. [CrossRef]

24. Chu, C.; Deng, J.; Hou, Y.; Xiang, L.; Wu, Y.; Qu, Y.; Man, Y. Application of PEG and EGCG modified collagen-base membrane to promote osteoblasts proliferation. Mater. Sci. Eng. C 2017, 76, 31-36. [CrossRef] [PubMed]

25. Lee, S.-H.; An, S.-J.; Lim, Y.-M.; Huh, J.-B. The efficacy of electron beam irradiated bacterial cellulose membranes as compared with collagen membranes on guided bone regeneration in peri-implant bone defects. Materials 2017, 10, 1018. [CrossRef] [PubMed]

26. Bielli, A.; Bernardini, R.; Varvarasc, D.; Rossic, P.; Di Blasi, G.; Petrella, G.; Buonomo, O.C.; Mattei, M.; Orlandi, A. Characterization of a new decellularized bovine pericardial biological mesh: Structural and mechanical properties. J. Mech. Behav. Biomed. Mater. 2018, 78, 420-426. [CrossRef] [PubMed]

27. Shi, Q.; Li, Y.; Sun, J.; Zhang, H.; Chen, L.; Chen, B.; Yang, H.; Wang, Z. The osteogenesis of bacterial cellulose scaffold loaded with bone morphogenetic protein. Biomaterials 2012, 33, 6644-6649. [CrossRef] [PubMed]

28. Tabor, A.J.; Robinson, A.; Pinto, B.I.; Kellar, R.S. Platelet Rich Plasma combined with electrospun collagen scaffold: In vivo and in vitro wound healing effects. Clin. Res. Dermal Open Access 2016, 3, 1-8.

29. Shiga, Y.; Kubota, G.; Orita, S.; Inage, K.; Kamoda, H.; Yamashita, M.; Yseki, T.; Ito, M.; Yamauchi, K.; Eguchi, Y.; et al. Freeze-dried human platelet-rich plasma retains activation and growth factor expression after eight week preservation period. Asian Spine J. 2017, 11, 329-336. [CrossRef] [PubMed]

30. Nurden, A.T.; Nurden, P.; Sanchez, M.; Andia, I.; Anitua, E. Platelets and wound healing. Front. Biosci. 2008, 13, 3532-3548. [CrossRef] [PubMed]

31. Song, Q.H.; Klepeis, V.E.; Nugent, M.A.; Trinkaus-Randall, V. TGF- $\beta 1$ regulates TGF- $\beta 1$ and FGF-2 mRNA expression during fibroblast wound healing. Mol. Pathol. 2002, 55, 164-176. [CrossRef] [PubMed] 
32. Anitua, E.; Sanchez, M.; Merayo-Lloves, J.; De la Fuente, M.; Muruzabal, F.; Orive, G. Plasma Rich in Growth Factors (PRGF-Endoret) stimulates proliferation and migration of primary keratocytes and conjunctival fibroblasts and inhibits and reverts TGF-1-induced myodifferentiation. Inves. Ophthal. Vis. Sci. 2011, 52, 6066-6073. [CrossRef] [PubMed]

33. Faramarzi, N.; Yazdi, I.K.; Nabavinia, M.; Gemma, A.; Fanelli, A.; Caizzone, A.; Ptaszek, L.M.; Sinha, I.; Khademhosseini, A.; Ruskin, J.N.; et al. Patient-specific bioinks for 3D bioprinting of tissue engineering scaffolds. Adv. Healthc. Mater. 2018, 7, e1701347. [CrossRef] [PubMed]

34. Zellin, G.; Linde, A. Effect of different osteopromotive membranes porosities on experimental bone neogenesis in rats. Biomaterials 1996, 17, 695-702. [CrossRef]

35. Zabrowska, M.; Bodin, A.; Backdahl, H.; Popp, J.; Golstein, A.; Gatenholm, P. Microporous bacterial cellulose as a potential scaffold for bone regeneration. Acta Biomater. 2010, 6, 2540-2547. [CrossRef] [PubMed]

36. Kontomaris, S.V.; Yova, D.; Stylianou, A.; Balagiannis, G. The effect of UV irradiation on collagen D-band revealed by Atomic Force Microscopy. Scanning 2015, 37, 101-111. [CrossRef] [PubMed]

37. Stylianou, A.; Yova, D. Surface nanoscale imaging of collagen thin films by Atomic Force Microscopy. Mater. Sci. Eng. C 2013, 33, 2947-2957. [CrossRef] [PubMed]

38. Murdock, K.; Martin, C.; Sun, W. Characterization of mechanical properties of pericardium tissue using planar biaxial tension and flexural deformation. J. Mech. Behav. Biomed. Mater. 2018, 77, 148-156. [CrossRef]

39. Chung, K.-Y.; Bhadriraju, K.; Spurlin, T.A.; Cook, R.F.; Plant, A.L. Nanomechanical properties of thin films of type I collagen fibrils. Langmuir 2010, 26, 3629-3636. [CrossRef] [PubMed]

40. Schmidt, C.E.; Baier, J.M. Acellular vascular tissues: Natural biomaterials for tissue repair and tissue engineering. Biomaterials 2000, 21, 2215-2231. [CrossRef]

41. Lopez-Garcia, M.D.C.; Beebe, D.J.; Crone, W.C. Young's modulus of collagen at slow displacement rates. Biomed. Mater. Eng. 2010, 20, 361-369. [PubMed]

42. An, Y.-Z.; Kim, Y.-K.; Lim, S.-M.; Heo, Y.-K.; Kwon, M.-K.; Cha, J.-K.; Lee, J.-S.; Jung, U.-W.; Choi, S.-H. Physicochemical properties and resorption progress of porcine skin-derived collagen membranes: In vitro and in vivo analysis. Dent. Mater. J. 2018, 37, 332-340. [CrossRef] [PubMed]

43. Liu, Z.Q.; Tuo, F.Y.; Song, L.; Liu, Y.X.; Dong, X.P.; Li, D.M.; Zhou, D.Y.; Shahidi, F. Action of trypsin on structural changes of collagen fibres from sea cucumber (Stichopus japonicus). Food Chem. 2018, 256, 113-118. [CrossRef] [PubMed] 